G522

PARTICIPATORY EVALUATION AND CO PRODUCTION MORE THAN THE SUM OF ITS PARTS?

${ }^{1,2} \mathrm{KL}$ Dharmarajah, 'S Blackstock, ' $\mathrm{M}$ Fawcett, ${ }^{1} \mathrm{~A}$ Soni, ${ }^{1} \mathrm{M}$ Watson, ${ }^{4,3} \mathrm{D}$ Hargreaves, 2,3 M Blair. ${ }^{1}$ Paediatrics, Imperial College NHS Trust, London, UKi ${ }^{2}$ Paediatrics, London North West NHS Trust, London, UK; ${ }^{3}$ Paediatrics, Imperial College London, London, UK; ${ }^{4}$ Paediatrics, University College Hospitals NHS Trust, London, UK

10.1136/archdischild-2020-rcpch.442

Introduction Peer or Participatory research (where patients take a more central role) is a useful method for investigating health promotion and health inequity and raising research quality. Co-production of health services is becoming more routine but equity in involvement of citizens in research and evaluation is lagging behind. This is even more stark in children and young people.

Our aim was to combine both approaches in an intervention to change behaviours around childhood obesity on a deprived local housing estate. This followed a 'what matters to me' approach and was conceptualised by local parents.

Methods Our integrated care collaborative supported parent volunteers to co-design and deliver a health and well-being intervention for local children. This was in the form of a 6week 'sprint' of exercise and healthy living activities. 2 young evaluators were identified and trained. They helped design, conduct and analyse a peer-led evaluation with repeat followup at 2 years. Their analysis was then triangulated with our formal evaluation. We used mixed methods with qualitative and quantitative assessment.

Results 26 children were recruited with 12 completing the programme and 7 followed to 2 years. Young people aged 12 and older universally felt they could communicate their views better in a focus group led by a local young person with established trust and agency. We observed the value of our peer evaluator's contribution to the design process and their insights during analysis.

Post programme there were improvements in physical activity and nutrition scores in participants using validated scores. At 2 years retention of the following themes were also identified; the value of healthy eating and cooking skills, on-going participation in activities, increased motivation to stay active, on-going friendships and sense of community.

Discussion The use of participatory evaluation in a citizendriven intervention allowed penetrance through some of the established barriers within hard to reach communities, as well as enabling more meaningful results. We have demonstrated the desirability and acceptability of participatory research with children and young people.This intervention also reinforces that small, community-designed and delivered initiatives have the power to effect behaviour change sustained at 2 years.

\section{G523 NOVEL METHOD TO BUILD CONSENSUS ON PRIORITIES FOR HEALTHCARE MEASUREMENT AND IMPROVEMENT BETWEEN CHILDREN, YOUNG PEOPLE, PARENTS AND PROFESSIONALS}

${ }^{1}$ E Wortley, ${ }^{1} \mathrm{~J}$ Ruzangi, ${ }^{2} \mathrm{E}$ Sparrow, 'DS Hargreaves. 'Primary Care and Public Health Department, Imperial College London, London, UK; ${ }^{2}$ Children and Young People's Engagement Team, RCPCH, London, UK

10.1136/archdischild-2020-rcpch.443
Aims It is widely seen as best practice for professionals and policymakers to develop and prioritise quality measures in equal partnership with patients. This rarely occurs with children and young people (CYP) - partly due to lack of validated consensus-building methodologies for use with CYP. We report a project to co-design and test a novel method for building consensus on the priorities for quality measurement and improvement in NHS services for CYP.

Methods Co-design: In partnership with RCPCH \&Us network, we developed a novel method, which drew on Delphi and Nominal Group Technique methodology. Key features to ensure equal participation included electronic voting, no advance reading, and a short, simple process.

Workshop Methods: 12 CYP (10-21 years), 6 parent/carers and 12 professionals attended a full-day workshop. Participants were selected for diversity of region, sex, ethnicity, experience of healthcare. Professionals included clinicians representing national bodies for paediatricians, GPs, paediatric nurses, health visitors, and health policy/regulation.

Participants voted anonymously via tablets on 32 measures. The importance of each measure was rated on a five-point scale. After a series of facilitated discussions and questions, voting was repeated.

Results Over 95\% participation was achieved for both rounds of voting and feedback on the process was positive. Despite marked differences in priorities between groups, consensus (defined as lower and upper quartiles within one point of the median score) was achieved for 29/32 measures in afternoon voting.

The highest afternoon scores were for contactability of their team for CYP with ongoing health needs (mean score 4.7/5) and the chance for CYP to see the doctor alone (4.7). Mean scores for the two lowest priorities decreased significantly after discussions: 4-hour wait in A\&E 3.7 (morning) 2.9 (afternoon), $\mathrm{p}=0.01$; annual weight monitoring for all 2-18 year olds 3.1 (morning), 2.2 (afternoon), $\mathrm{p}=0.02$.

Conclusions Consensus-building methodology is feasible for CYP, parents/carers and professionals. The importance of this exercise is reinforced by the fact that the top 2 measures are not routinely measured in any national frameworks, whereas the 2 measures rated least important are currently either measured or recommended.

Funding The Health Foundation

\section{G524 THE TEEN HEALTH TALK - A FEASIBILITY STUDY IN THE USE OF A BIOPSYCHOSOCIAL ASSESSMENT TOOL FOR ADOLESCENTS IN PRIMARY CARE}

${ }^{1} \mathrm{~S}$ Lamb, ${ }^{2} \mathrm{~A}$ Hagell, I I Wolfe. ${ }^{1}$ Children and Young Peoples Health Partnership, London, UK; ${ }^{2}$ Association of Young Peoples Health, London, UK

10.1136/archdischild-2020-rcpch.444

Aims The Teen Health Talk (THT) is a biopsychosocial assessment tool developed to promote better health assessments for young people (YP) at a young person's health hub. The aim was to assess the feasibility of using an abridged version in routine practice in Primary Care.

Method The THT is recorded on a template on a GP data system, EMIS, and provides prompts to the GP to help them conduct an effective adolescent consultation. The template was exported to 3 pilot sites (GP Practices) and each site was 